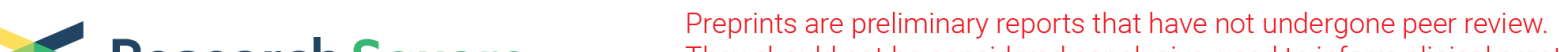 Research Square They should not be considered conclusive, used to inform clinical practice, or referenced by the media as validated information.
}

\section{Reduction of arsenic oxoanion toxicity from contaminated water by adsorption onto iron impregnated biochar}

Mohammad Hossien Salmani ( $\sim$ mhsn06@yahoo.com )

Shahid Sadoughi University of Medical Sciences and Health Services Yazd Research and Clinical Centre for Infertility https://orcid.org/0000-0002-2450-1278

Mohammad Abedi

Iranian Research Organization for Science and Technology

Sayed Ahmad Mozaffari

Iranian Research Organization for Science and Technology

Mohammad Javad Salmani

Shahid Bahonar University of Kerman

\section{Original article}

Keywords: Arsenic oxoanions, Contaminated water, Iron impregnation, Pomegranate peel, Adsorption mechanism

Posted Date: September 9th, 2020

DOl: https://doi.org/10.21203/rs.3.rs-66935/v1

License: (c) (1) This work is licensed under a Creative Commons Attribution 4.0 International License. Read Full License 


\section{Abstract}

Several ways have systematically been employed to modify carbons for removing heavy metal from contaminated solution. In the present study, Fe impregnated pomegranate peel carbon (Fe-PPC) as a green adsorbent was prepared by addition of $\mathrm{Fe}^{3+}$ ions into the pomegranate peel followed carbonization. Stability of iron on PPC was examined by releasing of Fe ions in aqueous solution at the $\mathrm{pH}$ range of 210. The effect of contact time, variable $\mathrm{pH}$, and initial concentration were studied in the adsorption of arsenite and arsenate anions by Fe-PPC. Maximum removal of arsenite and arsenate anions were observed in the $\mathrm{pH}$ range of 5-6 and 9-11 respectively which were $76.3 \%$ and $100 \%$. The elemental analysis and characterization of As -FePPC were performed by energy dispersive X-ray analysis (EDX) and BET. The adsorption rate $\left(\mathrm{v}_{0}\right)$ value indicated that the initial rates are suitable for arsenic anions adsorption on Fe-PPC in aqueous solution. The more than one mechanism was governed by the adsorption arsenate and was chemisorption, while the physical adsorption had the more contribution to the arsenite adsorption.

\section{Introduction}

Arsenic is a toxic metalloid that exists in the +3 and +5 oxidation states. It is present in the environment in a variety of minerals as oxyanions. Common environmental aqueous forms are arsenate $\left(\mathrm{AsO}_{4}{ }^{3-}\right)$ and arsenite $\left(\mathrm{AsO}_{3}{ }^{3-}\right)$, referred to as $\mathrm{As}(\mathrm{III})$ and $\mathrm{As}(\mathrm{V})$ anions. Arsenite predominates in reducing anaerobic environments and act as hard acid. Arsenate is stable in the oxygen-rich aerobic environment and behaves like a soft acid (Baig, Sheng et al. 2015). Arsenic compounds entered the environment due to the natural and anthropogenic activities (Smedley and Kinniburgh 2005, Chung, Yu et al. 2014). Long-term exposure to arsenic caused skin and circulatory problem, degenerative diseases and eve bladder, kidney, liver, and lungs cancer (Sun, Rathinasabapathi et al. 2014). In order to reduce health risk, World Health Organization (WHO) recommended a maximum contaminant level of total arsenic of $10 \mu \mathrm{g} . \mathrm{I}^{-1}$ in drinking water (WHO 2008). Also, it was reported that arsenic is toxic at low levels of $10^{-6}$ to $10^{-5} \mathrm{M}$ in natural and drinking water; thereby treatment of contaminated water to decrease the concentration of arsenic anions to the standard level $\left(10^{-6.87} \mathrm{M}\right)$ is necessary. Chemical precipitation is a common method to remove heavy metals from wastewaters. To reach a level below $10 \mu \mathrm{g} \cdot \mathrm{I}^{-1}$, a further additional process is required in the treatment of heavy metals after precipitation.

Recently, different methods have been examined for the treatment of waters contains a low concentration of heavy metal ions. Among them, adsorption is an efficient and effective method for removal of arsenic anions from aquatic environments. For the cost effective adsorption, modified carbon agricultural wastes have received great attention. Hence, several researches used cheap and stable iron-base support such as sand (Vaishya and Gupta 2003) cellulose (Guo and Chen 2005, Hokkanen, Repo et al. 2015), polymeric materials (Vatutsina, Soldatov et al. 2007), and magnetic biochar prepared from pinewood and natural hematite (Wang, Gao et al. 2015) for removal of arsenic anions. Also, different efforts have been made to impregnate iron into a carbon structure with various concentrations, in order to increase arsenic 
adsorption capacity; Chang et al. 2010 impregnated Fe(II) chloride in granular activated carbon; Chen et al. 2007 inserted $\mathrm{Fe}\left(\mathrm{NO}_{3}\right)_{3}$ in powder activated carbon; Fierro et al. 2009 used $\mathrm{Fe}$ (III) chloride for activation of carbon; Muniz et al. 2009 doped Fe(II) in commercial activated carbon but the doping iron into the agricultural wastes and carbonization was not used for removal of arsenic anions from aqueous solutions. In previous work, we found that pomegranate peel (PP) was an ideal support for iron loading because of the high content of polyphenols and the formation of stable complexes with the iron ions and after carbonization used for removal of $\mathrm{Cd}$ ions. The results showed 1.5 fold increases in removal efficiency of cadmium (Abedi, Salmani et al. 2016). Hence, the aim of this study is the investigation of iron impregnated to pomegranate peel carbon to adsorb arsenite and arsenate anions from aqueous solution for reducing the toxicity of arsenic oxoanions.

\section{Materials And Methods}

Pomegranate peels were procured from pomegranate gardens of Yazd city, Iran. All chemicals used in this study, including Fe (III) chloride, sodium arsenate, arsenic oxide, hydrochloric acid, and sodium hydroxide were analytical grades. Synthetic arsenate contaminated water was prepared with sodium arsenate whereas; synthetic arsenite water was prepared from arsenic oxide in $1 \mathrm{~N}$ sodium hydroxide in distilled water. For impregnation of $\mathrm{Fe}^{+3}$ ions into the pomegranate peels, the $10 \%(\mathrm{w} / \mathrm{v})$ solution of $\mathrm{FeCl}_{3}$ was prepared and after proper dilution was used. Batch experiments were conducted to investigate the adsorption of arsenite and arsenate onto the FePPC bioadsorbent. Adsorption equilibrium and long-time experiments were performed to evaluate the time equilibrium of FePPC for removal of arsenic anions. All experiments were carried out at $25^{\circ} \mathrm{C}$ and $150 \mathrm{RPM}$ in an orbital shaker. Arsenic analysis was performed via a Varian atomic absorption spectrometer 20AA at wavelength $197.2 \mathrm{~nm}$. Higher concentration of As (10-50 ppm) was analyzed by $\mathrm{N}_{2} \mathrm{O}-\mathrm{C}_{2} \mathrm{H}_{4}$ flame absorption spectrometer in a background correction mode. While the lower concentrations of As $(<10 \mathrm{ppm})$ were analyzed by graphite furnace atomic absorption (GFAA) spectrometer.

Nitrogen adsorption- desorption Brunauer- Emmett- Teller (BET) was used to determine the porosity, specific surface area, pore volume and diameter of Fe-PPC by Belsorp porosimeter. The measurements were performed at $77^{\circ} \mathrm{K}$ and saturated vapor pressure of $87.8 \mathrm{KPa}$ of $\mathrm{N}_{2}$ gas and the specimen was degassed in $300^{\circ} \mathrm{K}$. Barrett- Joyner- Halenda (BJH) method was used for the evaluation of the pore size distribution.

\section{Impregnation of pomegranate peel by $\mathrm{Fe}(\mathrm{III})$ ions}

The separated peels were thoroughly washed with water to remove any impurity on the peel surfaces. The peel samples gently dried at Lab temperature for a week in the absence of sunlight. The samples were ground using electrical mortar, sieved through a 40-60 mesh sieves and then heated in $70^{\circ} \mathrm{C}$ for $1 \mathrm{~h}$. These dried granules were used for impregnation of iron and modification of bioadsorbent. The modification procedure was conducted in two steps for loading iron into the PP to achieve optimum amount and stable impregnation ratio. First, $50 \mathrm{ml}$ of 1-5\% (w/V) $\mathrm{FeCl}_{3}$ solution was mixed with $50 \mathrm{~g} \mathrm{PP}$ 
granules until the peels were completely adsorbed the solution and after one night dried at $105^{\circ} \mathrm{C}$ for $3 \mathrm{~h}$. The solids were rinsed with distillate water 3 times to remove any un-reacted iron and chloride ions and again dried at $105^{\circ} \mathrm{C}$. Second, $10 \mathrm{~g}$ of PP impregnated with iron introduced to the crucible, and placed in the programmable furnace at atmosphere of nitrogen. The mixture was heated in the $400{ }^{\circ} \mathrm{C}$ and $3 \mathrm{~h}$ to be carbonized in the absence of air that this procedure was optimized in our previous work (Abedi, Salmani et al. 2016).

The stability of iron impregnated into the Fe-PPC was evaluated from the measurement of the iron released at different $\mathrm{pH}$ conditions. For each test, $0.2 \mathrm{~g}$ of Fe-PPC sample was introduced into the $100 \mathrm{ml}$ solution that its $\mathrm{pH}$ was initially adjusted at $2,4,7$, and 10 using suitable amounts of 1.0 or $0.1 \mathrm{M} \mathrm{HCl}$ or $\mathrm{NaOH}$. The suspension was shaken at a contact time of $8 \mathrm{~h}$ at $25^{\circ} \mathrm{C}$. The concentration of iron released from Fe-PPC was measured by AAS after filtering of suspension with $0.45 \mu \mathrm{m}$ filter. The percent of releasing iron was evaluated according to the mass of Fe-PPC.

\section{Adsorption experiments}

The effect of solution $\mathrm{pH}$ on the adsorption of arsenite and arsenate by Fe-PPC was investigated by varying the $\mathrm{pH}$ from 2 to 10 . For each test, $0.2 \mathrm{~g}$ of adsorbent was mixed with $100 \mathrm{ml} 20 \mathrm{mg} / \mathrm{l}$ of arsenite or arsenate solution in a series of Erlenmeyer, separately. The $\mathrm{pH}$ of the suspension was adjusted and the reaction vessels were shaken in an orbital shaker at $150 \mathrm{rpm}$ and $25^{\circ} \mathrm{C}$ and optimal contact time of $8 \mathrm{~h}$.

The kinetics experiments were recorded by adding $0.2 \mathrm{~g}$ of Fe-PPC to $50 \mathrm{ml}$ of $20 \mathrm{mg} / \mathrm{l}$ arsenite or arsenate solution. Adsorption experiments were carried out at $\mathrm{pH} 4$ for arsenite and $\mathrm{pH} 6$ for arsenate. The flasks were agitated on an orbital shaker at $150 \mathrm{rpm}$ and $25^{\circ} \mathrm{C}$. Each glass bottle was taken off the shaker at $0.25,0.5,1.0,1.5,2.0,4.0,8.0$ and $10 \mathrm{~h}$. To carry out adsorption isotherm experiments, the pH was set like the $\mathrm{pH}$ of kinetic tests. The same amount $(0.2 \mathrm{~g})$ of Fe-PPC was added to $50 \mathrm{ml}$ of arsenite or arsenate in range of $5,10,20,30$, and $50 \mathrm{mg} / \mathrm{l}$. The glass bottles were put in the shaker at $150 \mathrm{rpm}$ and $25^{\circ} \mathrm{C}$. After the end time of each experiment, the suspensions were filtered and the solutions were analyses at the end of the experiments, immediately.

\section{Results}

\section{Characterization of adsorbent}

The elemental analysis and physiochemical properties of prepared Fe-PPC adsorbent were studied by EDX and BET experiments. The EDX analysis of Fe-PPC adsorbent impregnated with $3 \%$ iron before and after adsorption of arsenate has been shown in Fig. 1 ( $a$ and $b$ ), respectively.

Fig. 1 the results of EDX analysis of Fe-PPC adsorbent impregnated with 3\% iron before (a) and after adsorption of arsenate ions (b). 
Nitrogen adsorption and desorption isotherm for Fe-PPC and its pore size distribution before and after adsorption of arsenate anions has been examined. Surface area, pore volume total and average pore diameter of Fe-PPC before and after adsorption of arsenate are represented in Table 1.

Table 1 Parameters obtained from BET and BJH methods for Fe-PPC before and after adsorption of arsenate anions

\begin{tabular}{llll}
\multicolumn{2}{l}{ Parameters } \\
\hline $\begin{array}{l}\mathrm{V}_{\text {nano }} \\
\left(\mathrm{cm}^{3} \cdot \mathrm{g}^{-1}\right)\end{array}$ & $\begin{array}{l}\mathrm{V}_{\text {total }} \\
\left(\mathrm{cm}^{3} \cdot \mathrm{g}^{-1}\right)\end{array}$ & $\begin{array}{l}\mathrm{S}_{\mathrm{BET}} \\
\left(\mathrm{m}^{2} \cdot \mathrm{g}^{-1}\right)\end{array}$ & Sample \\
\hline 3.85 & 4.05 & 314 & Fe-PPC \\
\hline 3.65 & 3.99 & 233 & Arsenate- Fe-PPC
\end{tabular}

\section{Effect of impregnated iron on adsorption of arsenite and arsenate anions}

For consideration the effect of the amount of impregnated iron on arsenite and arsenate removal by PPC, five adsorption tests with $1-5 \%(\mathrm{w} / \mathrm{v})$ of $\mathrm{FeCl}_{3}$ onto PPC were conducted. Fig. 2 shows the efficiency of Fe-PPC for removal of arsenite and arsenate anions as a function of $\mathrm{FeCl}_{3}$ concentration in preparation of Fe-PPC.

Fig. 2 The percent removal of arsenite and arsenate anions by Fe-PPC as a function of weight percent of $\mathrm{FeCl}_{3}$ for impregnation of iron into the PP

\section{Stability of impregnated iron in PPC}

The stability of impregnated iron in Fe-PPC that contained $6.0 \mathrm{mg}$ of iron in unite of mass was examined in four desorption tests at the same $\mathrm{pH}$ of adsorption experiments. According to the results in Table 2, the iron content of Fe-PPC nearly $0.56 \mathrm{mg} / \mathrm{L}$ was lost in desorption process when $\mathrm{pH}$ was 4 . At $\mathrm{pH} 2$, the releasing iron percent was $1.6 \mathrm{mg} / \mathrm{L}$.

Table 2 Releasing iron from Fe-PPC in different $\mathrm{pH}$ 


\begin{tabular}{lll}
$\mathrm{pH}$ & $\begin{array}{l}\text { Released Fe in solution } \\
(\mathrm{mg} / \mathrm{l})\end{array}$ & $\begin{array}{l}\text { \%w/w of releasing Fe } \\
(\mathrm{mg} / \mathrm{g})\end{array}$ \\
\hline 2 & 1.6 & 0.013 \\
\hline 4 & 0.56 & 0.0047 \\
\hline 7 & 0.28 & 0.0018 \\
\hline 10 & 0.38 & 0.0032
\end{tabular}

\section{Effect of contact time on arsenite and arsenate removal}

The relationship of contact time effect on arsenite and arsenate removal efficiency was studied and the results presented in Fig 3 . More than $58 \%$ and $78 \%$ of arsenite and arsenate was separately removed after $8 \mathrm{~h}$ of contact time at $\mathrm{pH}$ of 6 . Arsenate showed greater removal than arsenite in all ranges of contact times. For both anions, there were no significant differences in removal percentage at above of contact time of $8 \mathrm{~h}$. Therefore, this time was kept optimum for the further experiments.

Fig. 3 Effect of contact time on arsenite and arsenate removal

\section{Effect of initial concentration on arsenite and arsenate removal}

For evaluation of initial arsenic anions concentration on adsorption, the concentrations in the range of 10-50 mg/l were selected and the adsorption experiments were carried out. The calculated adsorption capacity and percentage removal at different concentration and $\mathrm{pH}$ of both anions is given in Table 3 . The removal of arsenate appears to be higher than $90 \%$ in the low concentration $(10 \mathrm{mg} / \mathrm{l})$.

Table 3 Adsorption capacity and removal efficiency of Fe-PPC as a function of different initial concentration and $\mathrm{pH}$ 


\begin{tabular}{|c|c|c|c|c|c|c|c|}
\hline & & As(III) & & & $\mathrm{As}(\mathrm{V})$ & & \\
\hline $\mathrm{C}_{0}(\mathrm{mg} / \mathrm{l})$ & $\mathrm{pH}$ & $\mathrm{Ce}(\mathrm{mg} / \mathrm{l})$ & $\% R$ & $\mathrm{q}(\mathrm{mg} / \mathrm{g})$ & $\mathrm{Ce}(\mathrm{mg} / \mathrm{l})$ & $\% R$ & $\mathrm{q}(\mathrm{mg} / \mathrm{g})$ \\
\hline 10 & & $1.5 \pm 0.1$ & 85 & $4.5 \pm 0.4$ & $1.6 \pm 0.2$ & 84 & $4.2 \pm 0.1$ \\
\hline 20.0 & 3.0 & $11.2 \pm 0.7$ & 63 & $9.4 \pm 0.3$ & $6.9 \pm 0.4$ & 77 & $11.5 \pm 0.4$ \\
\hline 50.0 & & $31.8 \pm 0.3$ & 36.5 & $9.1 \pm 0.6$ & $23.8 \pm 0.8$ & 52 & $11.9 \pm 0.5$ \\
\hline 10.0 & & $1.2 \pm 0.2$ & 88 & $4.4 \pm 0.3$ & $0.02 \pm 0.002$ & 99 & $5.0 \pm 0.1$ \\
\hline 20.0 & 6.0 & $14.2 \pm 0.7$ & 53 & $7.9 \pm 0.6$ & $1.01 \pm 0.1$ & 97 & $14.5 \pm 0.4$ \\
\hline 50.0 & & $33.4 \pm 0.7$ & 33 & $8.3 \pm .7$ & $21.4 \pm 0.5$ & 57 & $14.3 \pm 0.3$ \\
\hline 10.0 & & $3.2 \pm 0.2$ & 68 & $3.4 \pm 0.2$ & $3.2 \pm 0.2$ & 68 & $3.4 \pm 0.2$ \\
\hline 20.0 & 9.0 & $20.4 \pm 0.8$ & 32 & $4.8 \pm 0.3$ & $19.5 \pm 0.3$ & 35 & $4.6 \pm 0.5$ \\
\hline 50.0 & & $37.4 \pm 0.5$ & 25 & $6.3 \pm 0.5$ & $32.8 \pm 0.9$ & 34 & $8.8 \pm 0.7$ \\
\hline
\end{tabular}

\section{Effect of solution $\mathrm{pH}$ on arsenite and arsenate removal}

The results of the effect of $\mathrm{pH}$ on adsorption of arsenite and arsenate have been depicted in Fig 4. It reveals that for arsenite anions the adsorption was almost constant near $50 \%$ by increasing the solution $\mathrm{pH}$ from 2 to 8 and decreased to $23.6 \%$ at pH 10. While, for arsenate anions, the adsorption increased from $38 \%$ to $95.5 \%$ vigorously with increase of solution $\mathrm{pH}$ from $2-6$ and decreased to $30.2 \%$ at $\mathrm{pH} 10$.

Fig. 4 Effect of solution $\mathrm{pH}$ on removal of arsenite and arsenate by Fe-PPC

\section{Equilibrium isotherms and kinetic studies}

Several models are available to explain the isotherm behavior of adsorption process. Isotherms for arsenic biosorption on Fe-PPC were generally of the Langmuir or Freundlich types that adsorption constants of both models are listed in Table 5 .

Table 5 Langmuir and Freundlich constants and correlation coefficients for adsorption of arsenite and arsenate on Fe-PPC 


\begin{tabular}{llllllll} 
& Isotherm & \multicolumn{2}{c}{ Langmuir } & \multicolumn{4}{l}{ Freundlich } \\
\hline Adsorbent & $\mathrm{q}_{\mathrm{m}}$ & $\mathrm{b}$ & $\mathrm{R}^{2}$ & $\mathrm{n}$ & $\mathrm{K}_{\mathrm{F}}$ & $\mathrm{R}^{2}$ \\
\hline Arsenite & 5.55 & 16.46 & 0.981 & 0.852 & 2.34 & 0.640 \\
\hline Arsenate & 7.51 & 0.307 & 0.979 & 1.422 & 4.15 & 0.633
\end{tabular}

Also, the experimental data were correlated to pseudo-first order, and pseudo-second order equations. The parameters of $\mathrm{K}_{1}$ and $\mathrm{K}_{2}$ and $\mathrm{q}_{\mathrm{e}}$ were calculated from the slope and intercepts of the lines by plotting log $\left(q_{e}-q_{t}\right)$ and $t / q_{e}$ against $t$ and the parameters of $K_{\text {id }}$ and $q_{i d}$ were obtained from the plot of $q_{t}$ versus the square root of time $\left(\mathrm{t}^{1 / 2}\right)$ that all calculated parameters are listed in Table 7.

Table 7 Parameter value calculated using the kinetic models for the adsorption of arsenite and arsenate on Fe-PPC 


\begin{tabular}{|c|c|c|c|}
\hline \multirow[t]{2}{*}{ Models } & \multirow[t]{2}{*}{ Parameters } & \multicolumn{2}{|c|}{ Calculated values } \\
\hline & & Arsenite & Arsenate \\
\hline & $\mathrm{K}_{1}\left(\min ^{-1}\right)$ & 1.133 & 1.329 \\
\hline \multirow[t]{3}{*}{ pseudo- first order } & $\mathrm{q}_{\mathrm{e}}\left(\mathrm{mg} \cdot \mathrm{g}^{-1}\right)$ & 0.72 & 2.65 \\
\hline & $\mathrm{R}^{2}$ & 0.894 & 0.836 \\
\hline & $\mathrm{K}_{2}\left(\mathrm{~g} \cdot \mathrm{mg}^{-1} \cdot \mathrm{min}^{-1}\right)$ & 0.384 & 0.576 \\
\hline \multirow[t]{3}{*}{ pseudo- second order } & $q_{e}\left(m g \cdot g^{-1}\right)$ & 3.841 & 5.762 \\
\hline & $\mathrm{R}^{2}$ & 0.974 & 0.992 \\
\hline & $\mathrm{K}_{\mathrm{id}}\left(\mathrm{mg} \cdot \mathrm{g}^{-1} \cdot \mathrm{min}^{-1 / 2}\right)$ & 0.191 & 0.172 \\
\hline Intra-particle diffusion model & I & 0.006 & 0.003 \\
\hline \multicolumn{4}{|l|}{ Under $2 \mathrm{~h}$} \\
\hline & $\mathrm{R}^{2}$ & 0.919 & 0.979 \\
\hline & $\mathrm{K}_{\mathrm{id}}\left(\mathrm{mg} \cdot \mathrm{g}^{-1} \cdot \mathrm{min}^{-1 / 2}\right)$ & 0.040 & 0.028 \\
\hline Intra-particle diffusion model & I & 0.286 & 0.194 \\
\hline \multicolumn{4}{|l|}{ Up to $2 \mathrm{~h}$} \\
\hline & $R^{2}$ & 0.896 & 0.893 \\
\hline
\end{tabular}

The pseudo second-order model could best describe the kinetic results with $R^{2}=0.974$ and $R^{2}=0.992$ for arsenite and arsenate, respectively. Fig. 6 shows a linear plot of the linearized forms of the pseudosecond order model for adsorption of both anions on Fe-PPC.

Fig. 6 Linear plot of the pseudo-second order equation for adsorption of arsenite and arsenate

\section{Adsorption capacity of Fe-PPC}

The adsorption capacity of adsorbent is an important factor in the selection of a material as adsorbent. The plot of the adsorption capacity of Fe-PPC for adsorption of arsenite and arsenate has been presented 
in Fig. 5.

Fig. 5 The plot of qe vs Ce for adsorption of arsenite and arsenate

Arsenic species adsorption has been studied by various investigators, using a variety of different adsorbents. In Table 6 the respective adsorption capacities of common adsorbents are presented for comparison with the studied modified PPC biosorbent.

Table 6 Comparison of arsenic species adsorption on common adsorbents

\begin{tabular}{|c|c|c|c|c|c|c|c|}
\hline \multirow[b]{2}{*}{ adsorbent } & \multirow[b]{2}{*}{ Species } & \multirow[t]{2}{*}{$\mathrm{pH}$} & \multicolumn{2}{|c|}{ Freundlich } & \multicolumn{2}{|c|}{ Langmuir } & \multirow[t]{2}{*}{ Ref. } \\
\hline & & & $\mathrm{K}_{\mathrm{F}}$ & $1 / n$ & b & $q_{\max }$ & \\
\hline $\begin{array}{l}\text { Iron modified activated } \\
\text { carbon }\end{array}$ & Arsenate & 6.0 & 8.8 & 0.57 & 0.18 & 5.13 & $\begin{array}{l}\text { (Chen, Parette } \\
\text { et al. 2007) }\end{array}$ \\
\hline $\begin{array}{l}\text { Iron modified activated } \\
\text { carbon }\end{array}$ & Arsenite & 8.0 & 3.8 & 0.76 & 0.31 & 3.92 & $\begin{array}{l}\text { (Chen, Parette } \\
\text { et al. 2007) }\end{array}$ \\
\hline $\begin{array}{l}\text { Iron impregnated activated } \\
\text { carbon }\end{array}$ & Arsenate & 6.99 & - & - & 4.7 & 1.95 & $\begin{array}{l}\text { (Chang, Lin et } \\
\text { al. 2010) }\end{array}$ \\
\hline Iron impregnated PPC & Arsenate & 6.0 & 4.15 & 0.71 & 16.38 & 7.40 & Present work \\
\hline Iron impregnated PPC & Arsenite & 4.0 & 2.34 & 1.17 & 0.448 & 5.55 & Present work \\
\hline
\end{tabular}

\section{Discussion}

The EDX analysis of Fe-PPC adsorbent impregnated with 3\% iron before and after adsorption of arsenate indicated that the arsenate has been adsorbed by Fe-PPC (Fig. 1b). The specific surface area and pore volume of the compound were slightly reduced after adsorption of arsenate anions. In fact, arsenate adsorption leads to reduce of cavity space that caused change in the pore volume and specific surface area of Fe-PPC (Monárrez-Cordero, Amézaga-Madrid et al. 2016). According to the results of Table 1, the surface area was reduced from 314 to $233 \mathrm{~m}^{2} \cdot \mathrm{g}^{-1}$ and consequently a decrease in pore volume. High surface area of Fe-PPC $\left(314 \mathrm{~m}^{2} \cdot \mathrm{g}^{-1}\right)$ makes it a suitable adsorbent for removal of arsenite and arsenate anions. The high porosity percentage indicates that high surface area of adsorbent is due to the pore surface.

As it seen in Fig 1, arsenate removal increased as amount of impregnated iron increased, and reached to a maximum of $100 \%$ when the iron impregnated amount increased to $3 \%$ after that a decrease in removal of both anions occurred. Similar results were observed by Gu et al. (Gu, Fang et al. 2005) and Chang et al. (Chang, Lin et al. 2010) that arsenate removal optimized at Fe-AC with iron percent of $2.34 \%$ 
and $4.22 \%$. The result of the Muñiz, Fierro et al. (2009) study showed the lowest concentration of $\mathrm{FeCl}_{3}$ solution for treating of ACs was $0.2 \mathrm{M}$ that is similar to our finding.(Muñiz, Fierro et al. 2009). Iron desorption experiments indicated that treatment of PP with $\mathrm{Fe}^{3+}$ and them carbonized of the mixture was obtained a good stable composite. Depending on the results presented in Table 2, the iron content of FePPC, less than $0.005 \%$ was lost in the moderate $\mathrm{pH}$ solutions and it was very stable when $\mathrm{pH}$ was above 4.

For optimization of adsorption parameters, the one factor at the time procedure was conducted. In the present study, the contact time, $\mathrm{pH}$ and initial concentration were optimized and physical parameters as the rpm and temperature were constant at all experiments. The fast adsorption at the initial time of $2 \mathrm{~h}$ was due to the concentration gradient between the adsorbate in solution and the number of active sites available on the adsorbent surface at beginning of process. The progress of the process, increase adsorption of anions from the bulk solution and may be limited mass transfer of adsorbate anions from the liquid to the external surface of Fe-PPC. A time of $8 \mathrm{~h}$ was found to give optimum removal of arsenite and arsenate by Fe-PPC. While, Goel et al. 2004 reported that a time of $15 \mathrm{~h}$ obtained for optimum removal of arsenic by all activated carbons using to their study. A time of $8 \mathrm{~h}$ for arsenite and arsenate removal by Fe-PPC was a favorite contact time. Thus, the Fe-PPC is as efficient adsorbent for removal of arsenite and arsenate anions from aqueous solutions.

The results presented in Table 3, show that with increasing of initial concentration, the adsorption capacities increase while, removal efficiencies decrease linearly for both anions. This can be explained that adsorbent has a limited number of active sites, which become saturated at a certain concentration, while the ratio of the number of adsorbates to the active sites of adsorbent increase with the increasing of the initial concentration.

The effect of solution $\mathrm{pH}$ on arsenic anion adsorption was explained based on the species of adsorbate present in solution and the adsorbent surface chemistry in different $\mathrm{pH}$ ranges. The arsenite and arsenate species in different $\mathrm{pHs}$ have been represented in Table 4. Arsenite species in aqueous solution present mainly as $\mathrm{H}_{3} \mathrm{ASO}_{3}$ at $\mathrm{pH}$ less than 9 and above that as $\mathrm{H}_{2} \mathrm{ASO}_{3}{ }^{-}$and $\mathrm{ASO}_{3}{ }^{3-}$. Arsenate species in aqueous solution mainly present as $\mathrm{H}_{3} \mathrm{ASO}_{4}$ at pH less than 2.2, $\mathrm{H}_{2} \mathrm{ASO}_{4}{ }^{-}$at $\mathrm{pH}$ between $2.2-6.98, \mathrm{HAsO}_{4}{ }^{2-}$ at pH between 6.08- 11.5 and $\mathrm{ASO}_{4}{ }^{3-}$ at $\mathrm{pH}$ above 11.5 (Jadhav, Bringas et al. 2015).

Table 4 Adsorbent surface charges and arsenic species in aqueous solution at different pH 


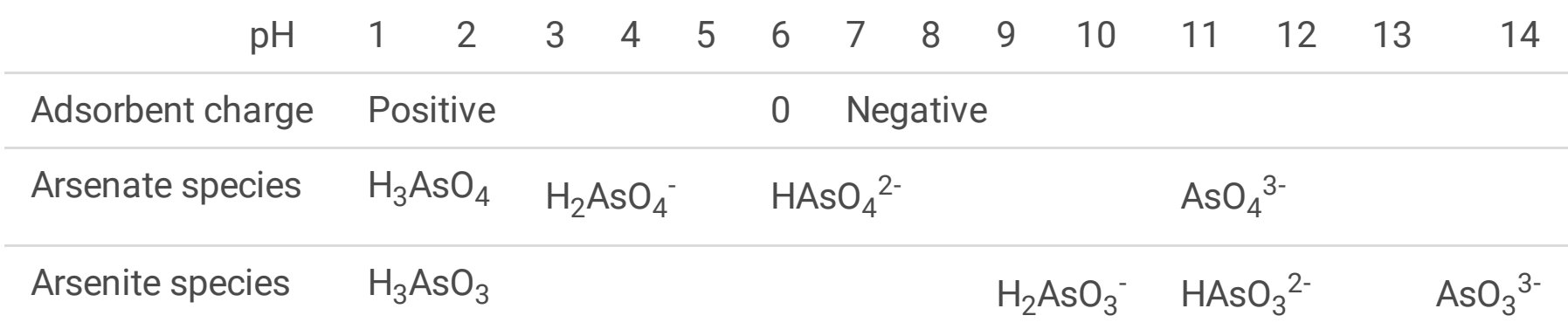

Adsorbent surface chemistry is described based on the zero point charge $\left(\mathrm{pH}_{\mathrm{zpc}}\right)$. The $\mathrm{pH}_{\mathrm{zpc}}$ is the $\mathrm{pH}$ that adsorbent has a net zero charge on the surface which is a fundamental importance in surface chemistry. According to the previous characteristic of the surface charge, the $\mathrm{pH}_{\mathrm{zpc}}$ for Fe-PPC was found to be 6.08 . Then, Fe-PPC has positively charged when $\mathrm{pH}$ is less than $\mathrm{pH}_{\mathrm{zpc}}(6.08)$ and able to adsorbed anions from the solution. While, $\mathrm{pH}$ is above $\mathrm{pH}_{\mathrm{zpc}}$, the surface has negatively charged and can react with cations in solution. According to Table 4, the electrostatic force between Fe-PPC and arsenate can occur at pH between 2.2 - 6.1 and changes to repulsion force when the $\mathrm{pH}$ increases above 6.1, and for arsenite occurs at $\mathrm{pH}$ between 2-8 and changes to repulsion force when the $\mathrm{pH}$ increases over 8 . The experimental results showed that effective removal of arsenate and arsenite anions occurred in the $\mathrm{pH}$ range of 2-6.

The equilibrium adsorption is an important parameter to design of adsorption system. Adsorption isotherm describes the equilibrium between adsorbent in the liquid and adsorbed on the surface of adsorbent at constant temperature. According to Table 5, the correlation coefficients of the Langmuir isotherm were 0.981 and 0.997 , and those for Freundlich model were 0.640 and 0.933 for arsenite and arsenate, respectively. This revealed the data were fitted better the Langmuir equation than Freundlich equation for both cases. Thus, the adsorption of arsenite and arsenate anions on the Fe-PPC obeyed the Langmuir adsorption isotherm. The value of $b$ was found to be 0.307 and 16.46 for arsenate and arsenite on Fe-PPC biosorbent, respectively. A high value of $b$ also implies strong bonding of arsenic to the modified biosorbent. The important characteristic of the Langmuir isotherm is a dimensional constant separation factor, $R_{L}$, which is defined as $R_{L}=1 /\left(1+b C_{0}\right)$. The $R_{L}$ value indicated the isotherm type and predicts whether an adsorption system is favorable $\left(0<R_{L}<1\right)$ or unfavorable $\left(R_{L}>1\right)$. The $R_{L}$ values were found to be 0.14 and 0.003 for concentration $20 \mathrm{mg} \mathrm{L}^{-1}$ of arsenate and arsenite adsorption on Fe-PPC which the isotherms are favorable for both anions.

The higher removal rate of arsenate (0.576) in contrast of arsenite (0.384) on $\mathrm{Fe}^{3+}-\mathrm{PPC}$ is due to the easy to the complex between arsenate and $\mathrm{Fe}^{3+}$-PPC sites. It is evident that the adsorption process under this condition is more suitable described by the pseudo second-order model which was based on the assumption that the rate limiting step may be chemisorption including valence forces through the exchange or sharing of electron between adsorbent and adsorbate (Khan, Chaudhry et al. 2015). The initial adsorption rate is an important constant factor, $\mathrm{v}_{0}$, which is defined as $\mathrm{v}_{0}=\mathrm{K}_{2} \mathrm{q}_{\mathrm{e}}{ }^{2}$. The $\mathrm{v}_{0}$ values 
were found to be 5.66 and $19.11 \mathrm{mg} .(\mathrm{g} \cdot \mathrm{min})^{-1}$ for arsenite and arsenate adsorption on Fe-PPC which the initial rate is suitable for both anions.

According to the intraparticle diffusion model, the correlation of adsorption capacity (q) with square root of time $\left(\mathrm{t}^{1 / 2}\right)$ should be linear if intraparticle diffusion is embraced to the adsorption mechanism. If the intercept of line is zero (line passes through the origin) then the intraparticle diffusion is the rate controlling step of the adsorption process (Wu, Tseng et al. 2009). As shown in Table 7, the correlation of adsorption capacity (q) with the square root of time $\left(\mathrm{t}^{1 / 2}\right)$ was linear and passed through the origin at times of under $2 \mathrm{~h}$. This suggested that until $2 \mathrm{~h}$ the intraparticle diffusion was the rate limiting on the adsorption system.

The $\mathrm{q}_{\max }$ is the maximum value of $\mathrm{q}_{\mathrm{e}}$ that is important and represents the monolayer saturation at equilibrium. The magnitude of $q_{\max }$ was found to be equal to $7.71 \mathrm{mg} \cdot \mathrm{g}^{-1}$ for the arsenate and $5.73 \mathrm{mg} . \mathrm{g}$

${ }^{1}$ for arsenite on the Fe-PPC, experimentally. These values have a good argument with the amount of $\mathrm{q}_{\mathrm{m}}$ from the Langmuir model (Table 5). Although a direct comparison between the examined iron modified absorbent with those obtained in the literature is difficult, due to the varying experimental conditions employed in those studies, the modified biosorbent used in the present study shows reasonably high adsorption capacity and binding energy constant, as compared with other adsorbents.

\section{Mechanism of arsenic oxyanion sorption}

Adsorption of arsenite and arsenate anions by Fe-PPC could be achieved by physical and chemical adsorption. Physical adsorption allows small solute particles and hydrophobic molecules to easily enter into the pores in adsorbent. The rate of diffusion into a pore depends on the size of particles and the degree of its hydrophobicity. This process depended on the pore size of Fe-PPC and radius of adsorbents. According to BET, it seems that carbonized Fe-PPC was a porous material that can well adsorb arsenate and arsenite with a radius of 4.2 and $4.8^{\circ} \mathrm{A}$, respectively. Hence, certain particles of arsenate and arsenite in solution can infiltrate on to the pores and across from one pore to the other.

Chemical adsorption, including reaction to iron oxides and reaction with other groups initially contained on the Fe-PPC surface, depended on the existing forms of the arsenic in solution and functional groups which specified by considering ZPC of the adsorbent material. In the $\mathrm{pH}$ range $2-7, \mathrm{H}_{2} \mathrm{AsO}_{4}{ }^{-}$was predominantly adsorbed. The adsorbent acquired positive charge in this $\mathrm{pH}$ range because the $\mathrm{pH}_{\mathrm{zpc}}$ of Fe-PPC was 6.3, and adsorption was facilitated by columbic interactions. In the $\mathrm{pH}$ range $2-7$, specific interactions occurred, since dissociation of arsenate is expected. The transfer of a proton to the hydroxyl groups of the Fe(III) hydroxide on the Fe-PPC surface is also possible. A surface complexation has also been proposed for arsenate adsorption on Fe-PPC biosorbent. So, arsenic species may be chemically removed from the iron hydroxides groups, which in this $\mathrm{pH}$ range are present as a cationic form of (PPC$\mathrm{Fe}(\mathrm{OH})_{2}^{+}$) on the surface of adsorbent through indicated schematically in the 1,2 , and 3 equations: 
$\mathrm{PPC}-\mathrm{FeOOH}_{2}{ }^{+}+\mathrm{H}_{2} \mathrm{AsO}_{4}{ }^{-}=\mathrm{PPC}-\mathrm{FeOOAsO}{ }_{3} \mathrm{H}_{2}+\mathrm{H}_{2} \mathrm{O}$

$\mathrm{PPC}-\left(\mathrm{FeOOH}_{2}^{+}\right)_{2}+\mathrm{H}_{2} \mathrm{AsO}_{4}^{-}=\mathrm{PPC}-\mathrm{Fe}_{2} \mathrm{O}_{2} \mathrm{AsO}_{2} \mathrm{H}_{2}+2 \mathrm{H}^{+}+2 \mathrm{H}_{2} \mathrm{O}$

Of course, other groups included carboxylic, phenolic, hydroxyl on the PPC that unreacted with $\mathrm{Fe}^{3+}$, are also supposed to be effective for arsenate removal in terms of the reactions 4,5 and 6 :

$\mathrm{PPC}-\mathrm{OH}+\mathrm{H}^{+}=\mathrm{PPC}-\mathrm{OH}_{2}{ }^{+} \quad$ at $\mathrm{pH}=2-7$

$\left.\mathrm{PPC}-\mathrm{OH}_{2}{ }^{+}+\mathrm{H}_{2} \mathrm{AsO}_{4}{ }^{-}=\mathrm{PPC}-\mathrm{OAsO}_{3} \mathrm{H}_{2}\right)+\mathrm{H}_{2} \mathrm{O} \quad$ inner sphere complex

PPC $-\left(\mathrm{OH}_{2}^{+}\right)_{2}+\mathrm{H}_{3} \mathrm{AsO}_{3}=\mathrm{PPC}-\mathrm{OHAsO}_{3} \mathrm{H}_{2}+\mathrm{H}_{2} \mathrm{O} \quad$ outer sphere complex

These routes are better for removal of arsenate than arsenite, since arsenite is generally available as neutral molecules at $\mathrm{pH}<9$, and a low number of active groups could be formed outer complex with arsenite molecules at $\mathrm{pH}<9$. This indicates the application of either physicochemical or diffusion for adsorption of anions into the pores, in order to increase the overall efficiency of the adsorption method.

The aforementioned reactions suggest that arsenic species is mainly adsorbed on Fe-PPC through specific adsorption (chemisorption), where the adsorbing of arsenate ions is bonded directly to the surface functional groups and caused the inner sphere complex formation. In the case of arsenite, where outer sphere complexes are probable to be formed, water molecules are present between the adsorbing anion and the surface functional groups. In study was conducted by Liu et al., they have suggested that arsenite can also form inner sphere complexes on Fe oxides, however, outer sphere complexes may also be probable to occur (Liu, Chuang et al. 2015).

The above simplified equations can describe the adsorption of arsenic species on Fe-PPC. In order to obtain a more detailed description of adsorption mechanism, studies are usually performed by macroscopic scale. The macroscopic adsorption phenomena are generally described on the basis of analysis of equilibrium data using adsorption isotherms (Thommes 2010). Isotherm models require a qualitative knowledge of functional groups composition and are dependent on the observed relationships between aqueous and adsorbed phases of the adsorbing species (Koretsky 2000). High regression correlation coefficients of Langmuir and Freundlich linear equation were found $(>0.93)$ for the Fe impregnation PPC, suggesting that both models are suitable for description of the biosorption equilibrium of arsenate ions by the modified PPC biosorbent. It is concluded that monolayer biosorption, as well as heterogeneous surface conditions may coexist under this experimental conditions (Rudzinski and Everett 2012).

Hence, the overall sorption of arsenate on the Fe-PPC is complex, involving more than one mechanism, such as ion exchange, surface complexation, electrostatic attraction and pore diffusion. Adsorption of oxyanions by modified PPC biosorbents was attributed to anion exchange on surface groups, resulting from the formation of a monolayer (Hiemstra and Van Riemsdijk 1999). The difference in the removal of 
arsenite and arsenate can be explained by the speciation differences. Arsenite is present as an anion exclusively above the $\mathrm{pH}$ value of 9.0 (Table 4), whereas in the $\mathrm{pH}$ range 2-9 only a small percentage of $\mathrm{H}_{3} \mathrm{AsO}_{3}$ is dissociated. Thus the effective parameter on treatment of arsenite from solution must be diffused into the pores. In addition, due to the fact that the arsenite has a larger radius than arsenate and attributed it to having a small diffusion compared to arsenate, consequence the physical adsorption has a contribution on the adsorption of two particles by Fe-PPC. This phenomenon caused maximum about $50 \%$ of both adsorbates removal from solution.

\section{Declarations}

\section{Ethic approval and consent to participate}

Not applicable

\section{Consent for publication}

All the authors have given consent for the publication of the manuscript.

\section{Availability of data and material}

Not applicable

\section{Competing interests}

No competing financial interests exist.

\section{Funding}

This work was supported by the Health Faculty of Shahid Sadoughi University of Medical Science and Iranian Research Organization for Science and Technology

\section{Authors' contributions}

MHS and MA contributed to conception and design of the study and performed the statistical analysis. MHS and MJS performed the experiments. MHS, MA and SAM wrote the manuscript. All authors contributed to manuscript revision. All authors read and approved the final manuscript.

\section{Acknowledgment}

The authors are grateful for the financial support from the Health Faculty of Shahid Sadoughi University and Iranian Research Organization for Science and Technology.

\section{Authors' information}


${ }^{1}$ Environmental Science and Technology Research, Department of Environmental Health Engineering, Shahid Sadoughi University of Medical Science, Yazd, I. R. Iran. ${ }^{2}$ Department of Chemical Technologies, Iranian Research Organization for Science and Technology (IROST), Tehran, I. R. Iran. ${ }^{3}$ Department of Chemical Technologies, Iranian Research Organization for Science and Technology (IROST), Tehran, I. R. Iran. ${ }^{4}$ Faculty of Veterinary Medicine, Shahid Bahonar University of Kerman, Kerman, I. R. Iran,

\section{References}

Abedi, M, Salmani, M H, and Mozaffari S A (2016), Adsorption of Cd ions from aqueous solutions by iron modified pomegranate peel carbons: kinetic and thermodynamic studies, Inter J Environ Sci Technol, 13 (8), 2045-56.

Chang Q., Lin W., and Ying, W-chi (2010), Preparation of iron-impregnated granular activated carbon for arsenic removal from drinking water, $J$ Hazard Mater, 184 (1), 515-22.

Chen W., Parette R., Zou ., Cannon FS., and Dempsy BA., (2007), Arsenic removal by iron-modified activated carbon, Water Res, 41 (9), 1851-58.

Choong, Thomas S. Y., Chuah TG, Robiah Y, Gregory Koay FL, an Azni I., (2007), 'Arsenic toxicity, health hazards and removal techniques from water: an overview', Desalination, 217 (1-3), 139-66.

Fierro V, Muniz G., Gonzalez-Sanchez G., Ballinas M., and Celzard A., (2009), Arsenic removal by irondoped activated carbons prepared by ferric chloride forced hydrolysis, J Hazard Mater, 168 (1), 430-37.

Goldberg S., and Johnston, Cliff T (2001), 'Mechanisms of arsenic adsorption on amorphous oxides evaluated using macroscopic measurements, vibrational spectroscopy, and surface complexation modeling', J colloid and Interface Sci, 234 (1), 204-16.

Gu Z., Fang J., and Deng B., (2005), Preparation and evaluation of GAC-based iron-containing adsorbents for arsenic removal, Environ Sci Ttechnol, 39 (10), 3833-43.

Guo X., and Chen F., (2005), Removal of arsenic by bead cellulose loaded with iron oxyhydroxide from groundwater, Environ Sci Technol, 39 (17), 6808-18.

Hiemstra, T and Van Riemsdijk, WH (1999), Surface structural ion adsorption modeling of competitive binding of oxyanions by metal (hydr) oxides, J Colloid Interf Sci, 210 (1), 182-93.

Ho, YS and McKay, G (1999), Comparative sorption kinetic studies of dye and aromatic compounds onto fly ash, J Environ Sci \& Health Part A, 34 (5), 1179-204.

Jain C. K. and Ali I., (2000), Arsenic: occurrence, toxicity and speciation techniques, Water Res, 34 (17), 4304-12. 
Katsoyiannis I. A. and Zouboulis A. I., (2002), Removal of arsenic from contaminated water sources by sorption onto iron-oxide-coated polymeric materials, Water Res, 36 (20), 5141-55.

Koretsky, C (2000), The significance of surface complexation reactions in hydrologic systems: a geochemist's perspective, J Hydrol, 230 (3), 127-71.

Monárrez-Cordero BE, Amézaga-Madrid P, Leyva-Porras CC, Pizá-Ruiz P, Miki-Yoshida M. (2016), Study of the Adsorption of Arsenic (III and V) by Magnetite Nanoparticles Synthetized via AACVD, Mater Res, 19, 103-12.

Muñiz G, Fierro V, Celzard A, Furdin G, Gonzalez-Sánchez G, Ballinas M., (2009), Synthesis, characterization and performance in arsenic removal of iron-doped activated carbons prepared by impregnation with Fe (III) and Fe (II), J Hazard Mater, 165 (1), 893-902.

Muñoz J. A., Gonzalo A., and Valiente M. (2002), Arsenic adsorption by Fe (III)-loaded open-celled cellulose sponge. Thermodynamic and selectivity aspects, Environ Sci Technol, 36 (15), 3405-11.

Nordstrom D. K., (2002), 'Worldwide occurrences of arsenic in ground water', Science (Washington), 296 (5576), 2143-45.

Ratnaike R. N., (2003), Acute and chronic arsenic toxicity, Postgrad Med J, 79 (933), 391-96.

Roy P. and Saha, A. (2002), Metabolism and toxicity of arsenic: A human carcinogen, Curr Sci, 82 (1), 3845.

Rudzinski W., and Everett D H., (2012), Adsorption of gases on heterogeneous surfaces (Academic Press).

Thommes M., (2010), 'Physical adsorption characterization of nanoporous materials', Chem. Ing. Tech, 82 (7), 1059-73.

Vaishya R. C. and Gupta S. K., (2003), Arsenic removal from groundwater by iron impregnated sand, $J$ Environ Eng, 129 (1), 89-92.

WHO (2008), Guidelines for drinking-water quality, recommendations, 4nd, World Health Organization, Geneva.

Wu F-C., Tseng, Ru-L., and Juang R.S., (2009), Initial behavior of intraparticle diffusion model used in the description of adsorption kinetics, Chem Eng J, 153 (1), 1-8.

Zouboulis A. I and Katsoyiannis I. A., (2002), Arsenic removal using iron oxide loaded alginate beads', Ind Eng Chem Res, 41 (24), 6149-55.

\section{Figures}



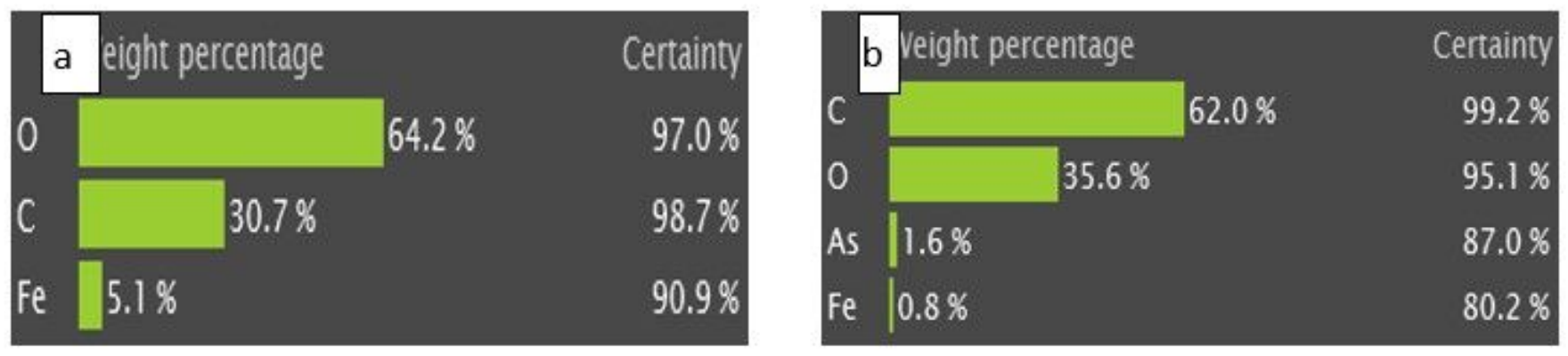

\section{Figure 1}

the results of EDX analysis of Fe-PPC adsorbent impregnated with $3 \%$ iron before (a) and after adsorption of arsenate ions (b).

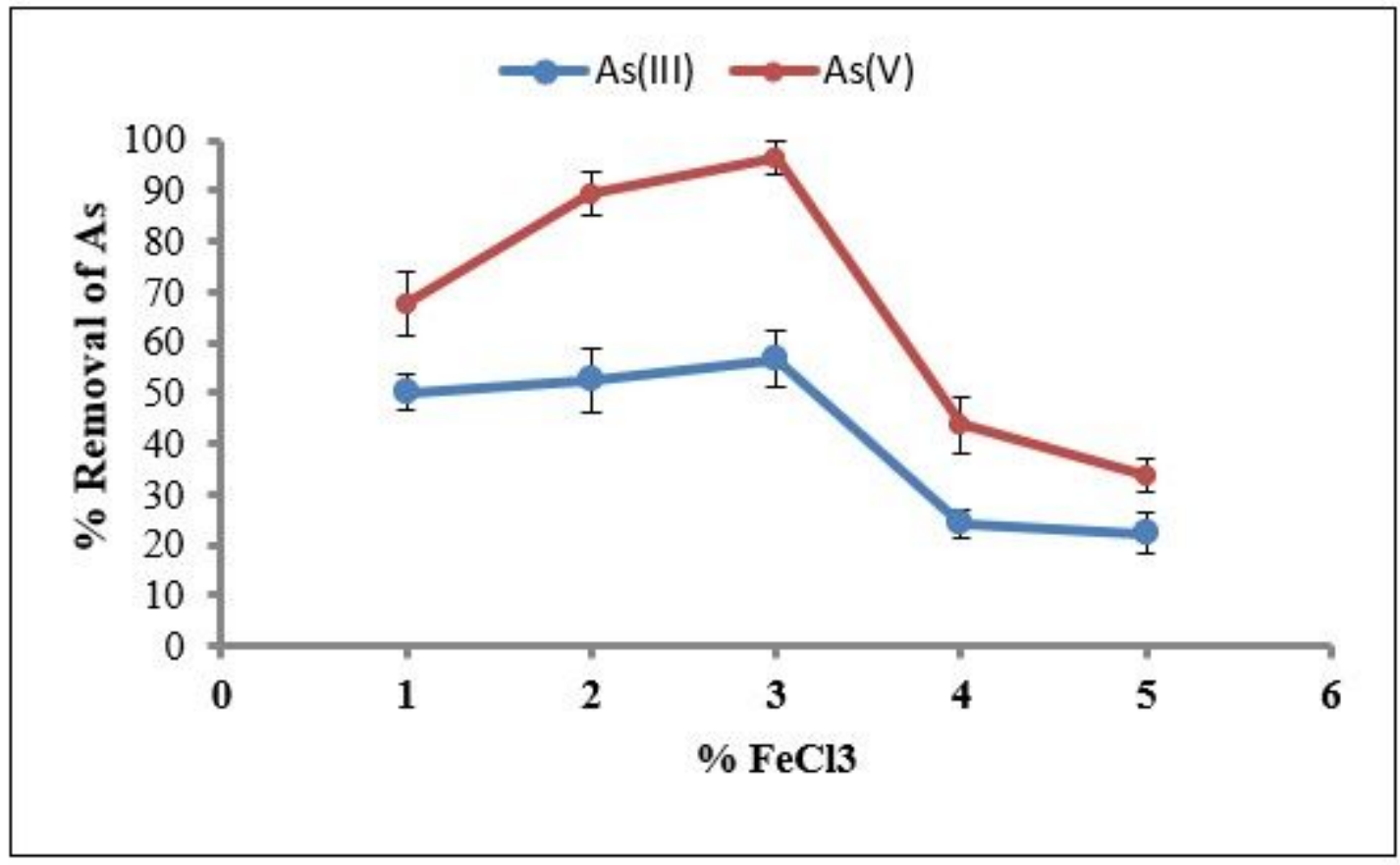

Figure 2

The percent removal of arsenite and arsenate anions by Fe-PPC as a function of weight percent of $\mathrm{FeCl} 3$ for impregnation of iron into the PP 


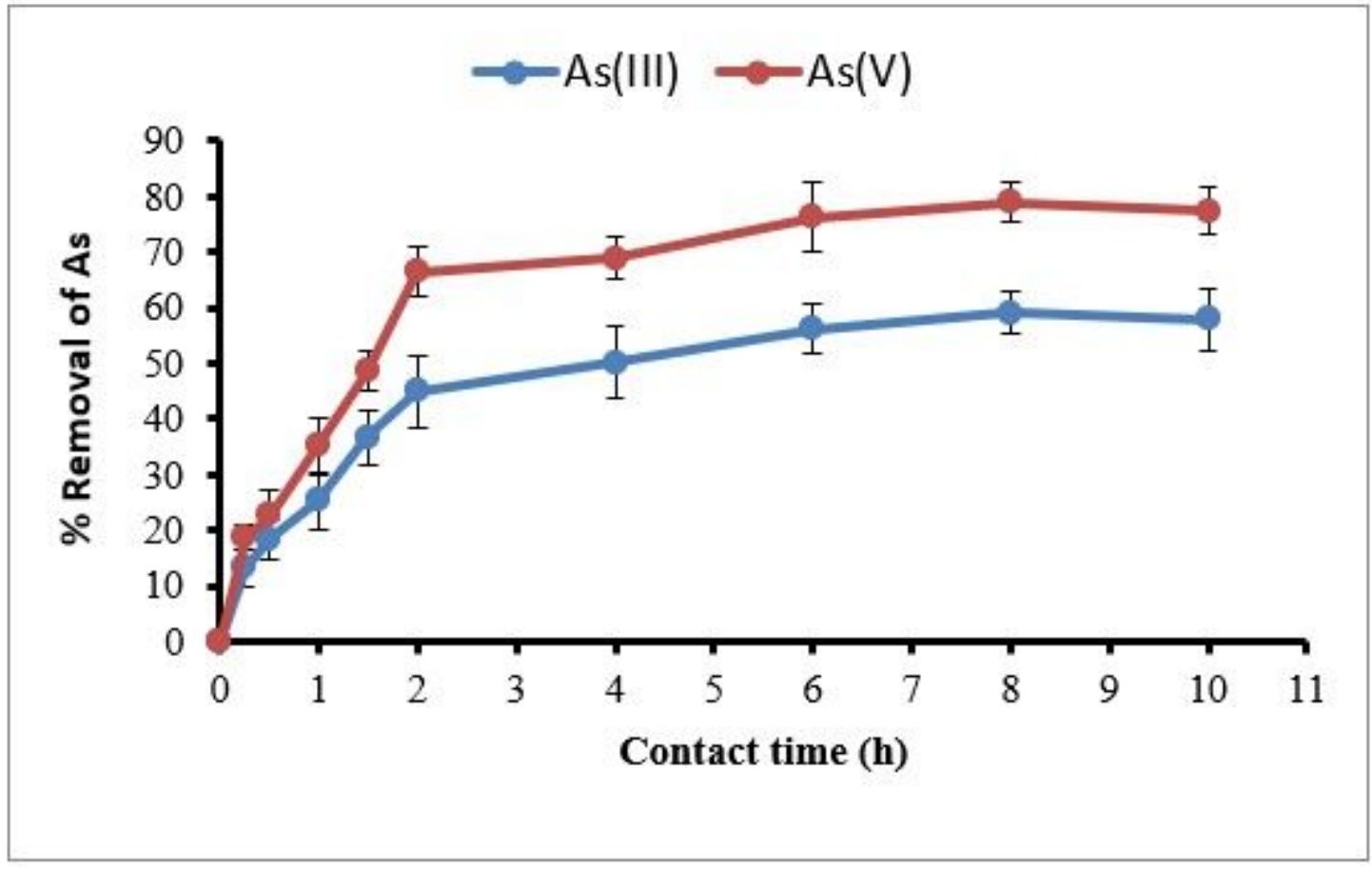

Figure 3

Effect of contact time on arsenite and arsenate removal

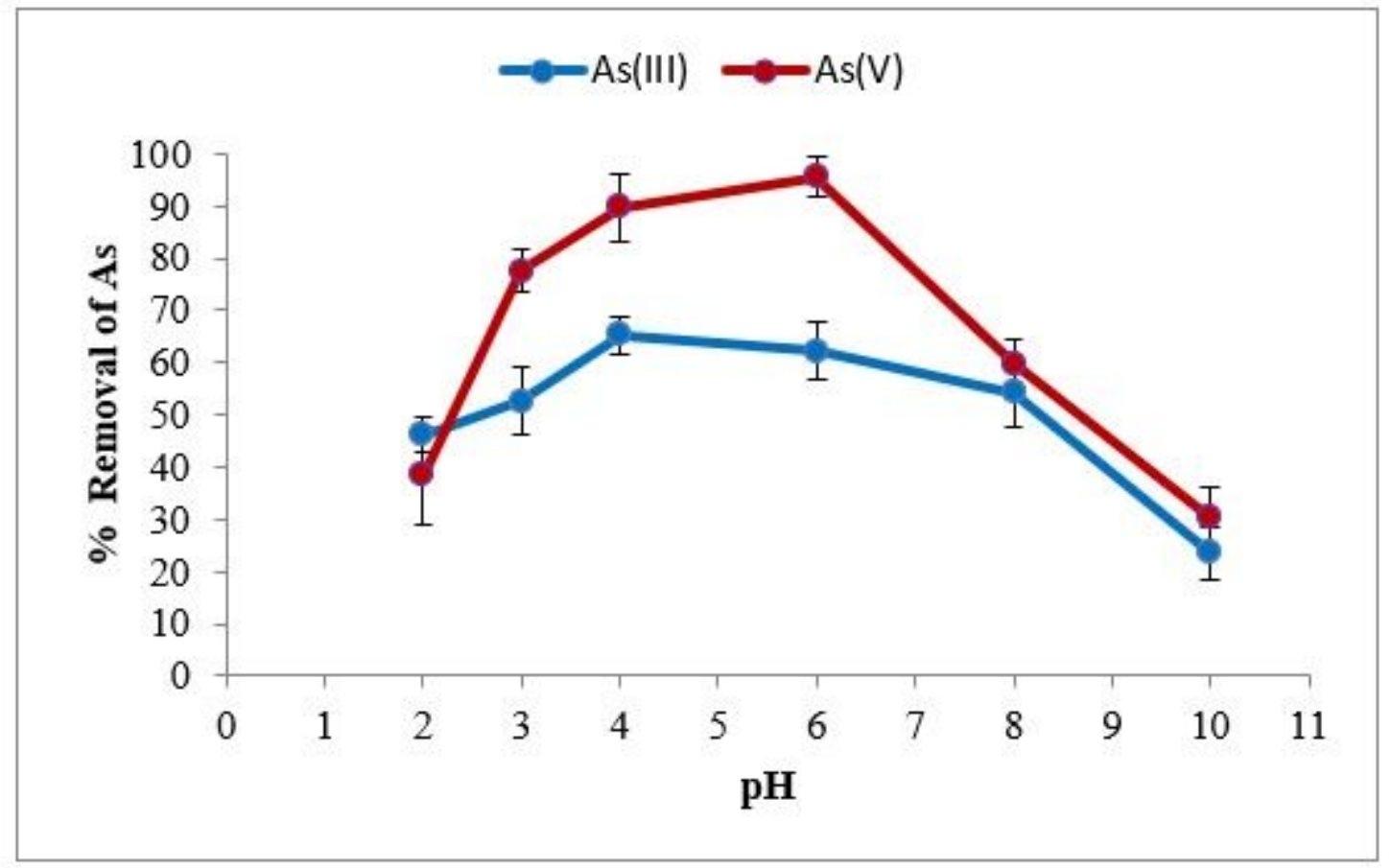

Figure 4 
Effect of solution $\mathrm{pH}$ on removal of arsenite and arsenate by Fe-PPC

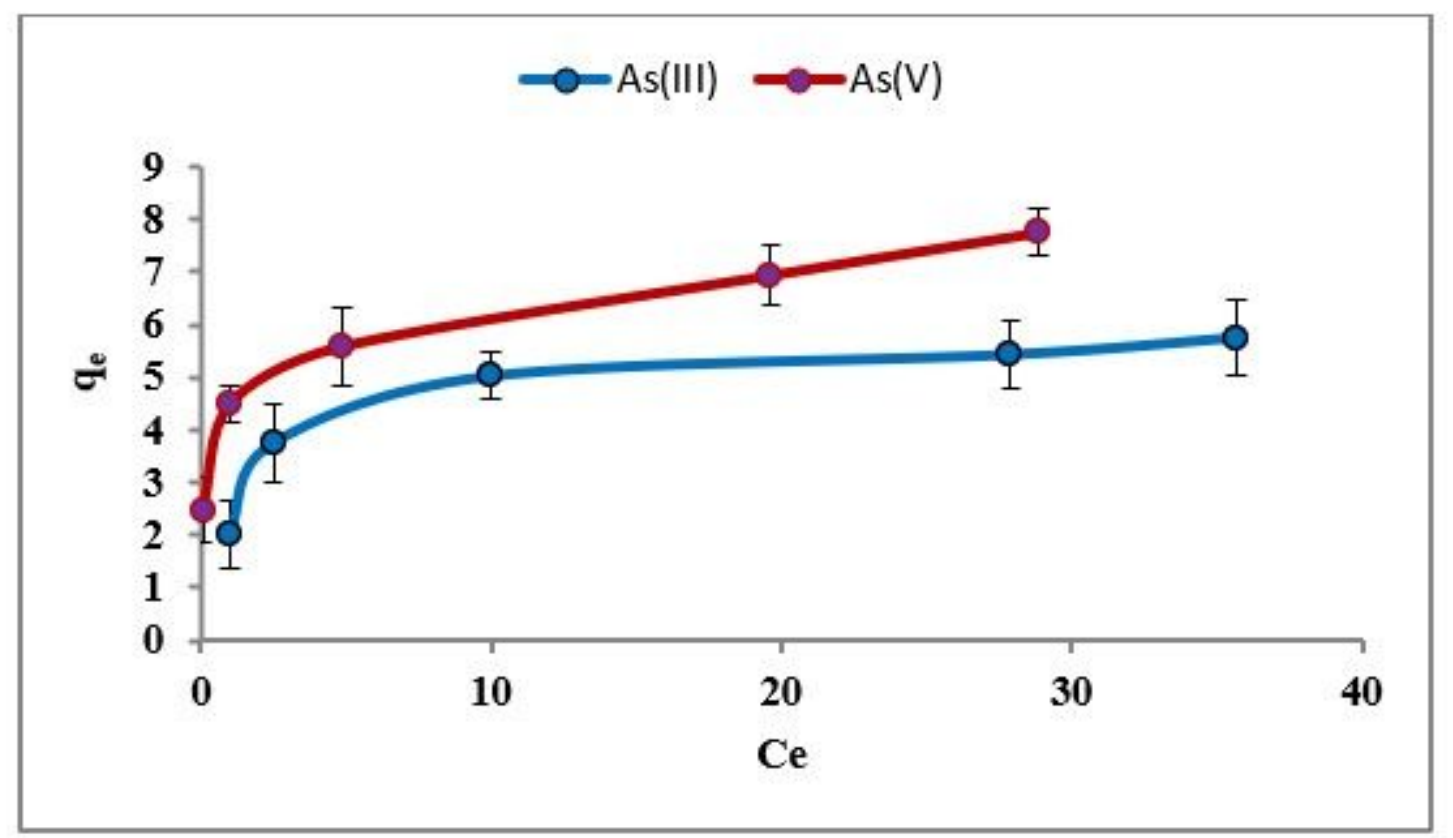

Figure 5

The plot of qe vs Ce for adsorption of arsenite and arsenate

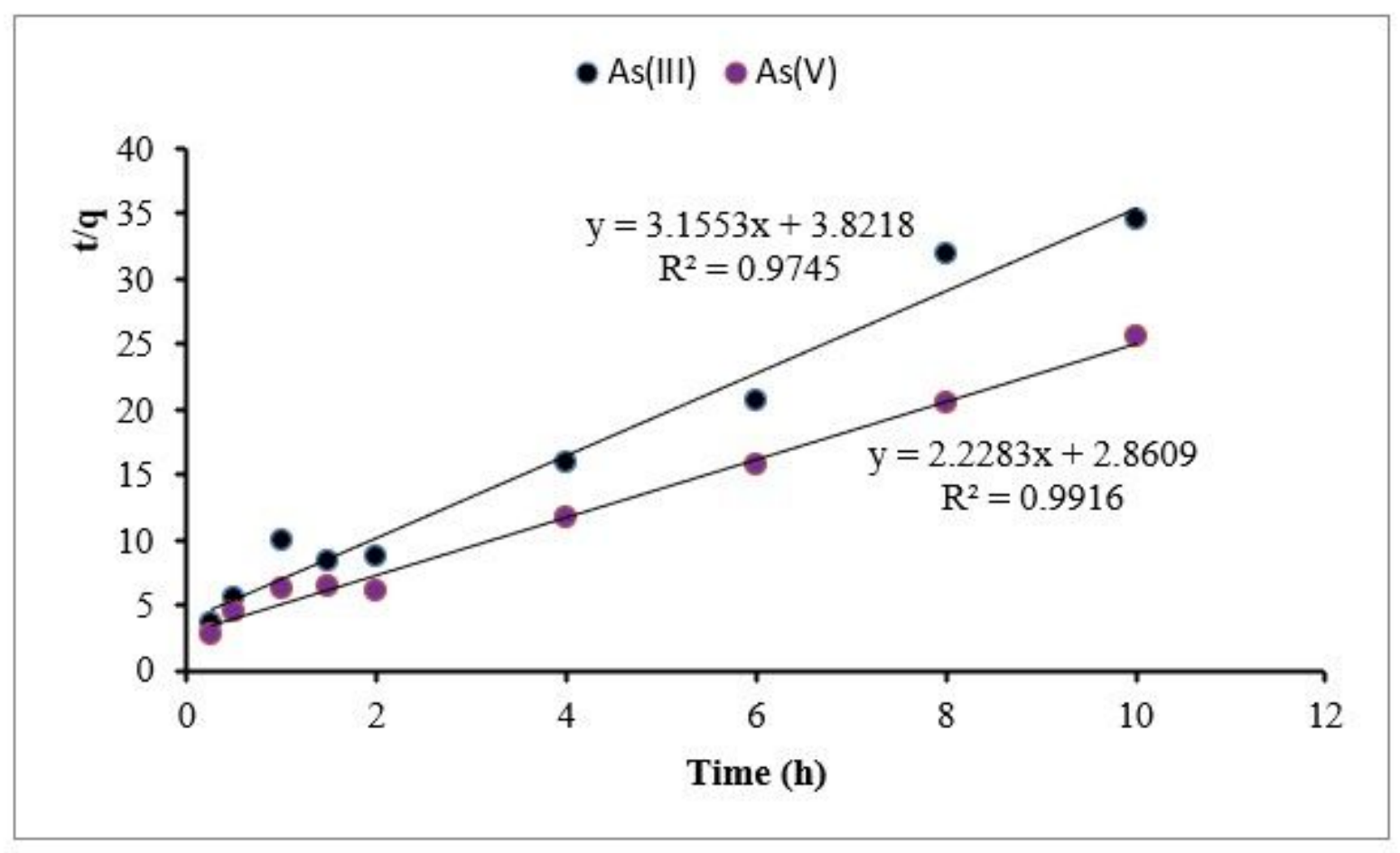

Figure 6 
Linear plot of the pseudo-second order equation for adsorption of arsenite and arsenate 